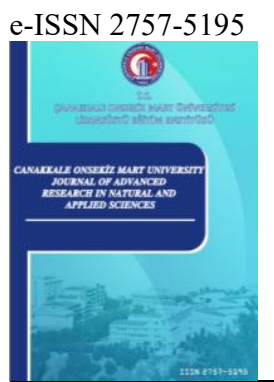

Çanakkale Onsekiz Mart University

Journal of Advanced Research in Natural and Applied Sciences

Open Access

\title{
İş Sağlı̆̆ı ve Güvenliğinde Güvenlik İkliminin Belirlenmesinde Kadercilik Algısının Rolü: Kimya Bölümü Öğrencileri Üzerine Bir Uygulama
}

\author{
Gülizar Hoşten ${ }^{1}$, Necla Dalbay ${ }^{2 *}$ \\ ${ }^{1}$ İș Sağlığı ve Güvenliği Doktora Programı, Sağlık Hizmetleri Meslek Yüksek Okulu, İstanbul Aydın Üniversitesi, İstanbul, Türkiye \\ ${ }^{2}$ İş Sağlığı ve Güvenliği Bölümü, Lisansüstü Eğitim Enstitüsü, İstanbul Aydın Üniversitesi, İstanbul, Türkiye
}

$\begin{array}{lr}\text { Makale Tarihçesi } \\ \text { Gönderim: } & 29.04 .2021 \\ \text { Kabul: } & 24.08 .2021 \\ \text { Yayım: } & 15.12 .2021\end{array}$

Araștırma Makalesi
Öz - Çalışma alanlarında güvenli ortamların sağlanabilmesi için gerekli olan güçlü güvenlik kültürü olumlu güvenlik iklimine ihtiyaç duyar. Olumlu güvenlik iklimi güvenlikle ilgili önlemlerin önceden alınarak örgütsel, yönetimsel ve sosyal alanlarda uygulanması ile gerçekleşir. Bu çalışmanın amacı; güvenlik ikliminin alt faktörlerinden biri olan kadercilik algısını, üniversitelerin kimya bölümünde eğitim alan lisans ve lisansüstü öğrencilerinin değerlendirmeleriyle açıklamaya çalışmaktır. Risk algısı kişinin tehlike veya riskle karşılaştığında yaralanma veya hastalanma ihtimalini düşünmesidir ve daha önce yaşanan kaza tecrübelerinden etkilenerek güvenli davranışlar geliștirmesine yardımcı olur. Kadercilik algısında ise olacakların önüne geçilemeyeceği düsüncesi ön plandadır. Akademik ortamda kullanılan laboratuvarlar öğrencilerin oluşabilecek tüm tehlike ve risklere karşı üst düzeyde önlemlerin alındığı güvenli ortamlar olmasına rağmen, öğrencilerin hazır bulunurlukları mezuniyet sonrası sanayii ve endüstride görev yapacak genç kimyagerlerin sahip oldukları güvenlik anlayışlarını ve topluma nasıl yön vereceklerini anlamak açısından önemlidir. Farklı üniversitelerin kimya bölümlerinde eğitim alan öğrencilerden güvenlik algısı kapsamında toplanan verilere kadercilik alt faktörünü açıklamak ve tanımlayabilmek için faktör analizi yapılmıștır. Öğrencilerin kadercilik davranışları arasında fark olup olmadığı Pearson korelasyon yöntemi ile test edilmiştir. Seçilen demografik faktörlerin değerlendirilmesi için tek yönlü varyans analizi (One-way ANOVA) testi kullanılmıştır. Bu çalışmada ölçülen kadercilik faktörü ortalama değeri kimya bölümü öğrencilerinin kazaları değerlendirirken kaderci bir yaklaşım izlemediklerini ve kazaların önlenmesi konusunda yönetimi ve üniversite ortamının yanı sıra kendilerini de sorumlu olarak gördüklerini göstermektedir. Ayrıca bu çalışmada kadercilik algısı bağlamında öğrencilerin eğitim gördükleri üniversitelerden bağımsız olarak ortak bir eğilim gösterdiği görülmektedir. Bu çalışmada edinilen başka bir sonuç da verilen iş sağlığı ve güvenliğgi eğitimlerinin öğrencilerin ihtiyaçlarını karşılayacak yeterli seviyede olmadı̆̆ıdır.

Anahtar Kelimeler - Güvenlik iklimi, iş sağllğı ve güvenliği, kadercilik algısı, kimya bölümü, tehlike ve riskler

\section{The Role of Perception of Fatalism in Determining the Safety Climate in Occupational Health and Safety: An Application on Chemistry Department Students}

${ }^{1}$ Occupational Health and Safety Doctorate Degree Program, Vocational School of Health Services, İstanbul Aydin University, İstanbul, Turkey

${ }^{2}$ Institude of Graduate Studies, Occupational Health and Safety Department, İstanbul Aydin University, İstanbul, Turkey

Article History

Received: $\quad 29.04 .2021$

Accepted: $\quad 24.08 .2021$

Published: $\quad 15.12 .2021$

Research Article
Abstract - A strong safety culture needs a positive safety climate. Positive safety climate is depending on taking precautions and applying them in organizational, administrative and social areas. The aim of this study is to explain the perception of fatalism for measuring the safety climate, with the evaluations of students who are studying in the chemistry department of universities. Risk perception is thinking of the possibility of injury or illness when the individual faced with danger and helps him develop safe behaviours by being influenced of the result of previous accident experiences. In the perception of fatalism, the idea that what will happen cannot be prevented is at the forefront. Although the academic laboratories are safe environments, the readiness of the students will show us safety perceptions of young chemists, who will work in industry, and how they will influence the society. ANOVA and a Pearson correlation were used to determine the safety behaviour and to determine whether there was a relationship between students in different universities. This study shows that the students of the chemistry department do not follow a fatalistic approach when evaluating the accidents and they see themselves as responsible for the prevention of accidents, as well as the management and the university environment. In addition, it is seen that there is loyalty among universities in the context of the perception of fatalism. Another result of this study is that the occupational health and safety trainings are not at a sufficient level to meet the needs of students.

Keywords - Safety climate, occupational health and safety, fatalism perception, chemistry department, hazards and risks

ghosten@stu.aydin.edu.tr

2 (iD) necladalbay@aydin.edu.tr

* Sorumlu Yazar/Corresponding Author 


\section{Giriş}

Uluslararası Çalışma Örgütü (UÇÖ) verilerine göre tüm dünyada her bir saniyede 11 iş kazası yaşanmakta ve 5 çalışan işle ilgili hastalıklara yakalanmaktadır (ILO Statistics and Database, 2020). Meslek hastalıkları ve iş kazasına uğrayan kişinin bireysel olarak çektiği acılar ve zorlukların yanı sıra ailesine, toplumdaki diğer bireylere, çalıştığı kuruma, bağlı bulunduğu sosyal güvenlik kurumuna ve devlete olan etkileri ve maliyeti de oldukça yüksektir. Bu durumun uzun vadede küresel anlamda gayri safi hasılatın \%3.94 lük bir bölümünü oluşturan ciddi mali sorunlara yol açacağ öngörülmektedir. UÇÖ’nün 155 ve 161 nolu sözleşmeleri ve 89/391/EEC sayılı Avrupa Birliği Çerçeve/Konsey Direktifi ile doğru orantılı olarak çıkartılan ve 2012 yılında yürürlüğe giren 6331 sayılı İş Sağlığ ve Güvenliği (ISSG) kanunu ile ülkemiz çalışanların güvenlikleri koruma altına alınmıştır. Uluslararası sözleşmelerin uygulanmaya başlama tarihlerine bakıldığında ülkemizle aradaki farkın 30 yıldan fazla olduğu görülmektedir. Bu durum Türkiye'ye bilimsel anlamda kullanabileceği yöntemler bağlamında bazı avantajlar sağlamasının yanı sıra alınacak önlemler konusunda da rol gösterici olmaktadır.

\subsection{Güvenlik İklimi ve Kültürü}

İş kazası ve meslek hastalığı nedeniyle sekteye uğrayacak iş süreçleri, zarar görecek itibarları ve bütçelerinden çıkacak para yerine sahip oldukları tüm bu değerleri işlerini geliştirmek için kullanmak isteyen işverenler özellikle son yıllarda örgütsel, yönetimsel ve sosyal anlamda güvenlik uygulamalarının önemini ve farkındalığını artırmaya başlamıştır. Güvenlik uygulamaları her geçen gün daha hassas, daha planlı ve önceden önlemlerin alınması ile daha güvenilir bir çalışma çevresi yaratmaktadır. Güvenlik uygulamalarını etkileyen faktörleri bulmak, onları ölçülebilir hale getirmek ve uygulama alanlarını genişletmek için sürekli olarak çalışmalar yapılmaktadır.

Bir kurum ve kuruluşun çalışanları tarafından kendilerini güvende hissederek o kurumda varlıklarını sürdürebilmeleri farklı boyutların düzenli ve birbirinin içine geçmiş şekilde birlikte var olabilmeleri ile mümkündür. Yapılan literatür çalışması bu konuda ilk çalışmalardan birinin İsrailli bilim adamı Dov Zohar'a ait olduğunu ortaya koymaktadır. Zohar güvenlik algısını oluşturarak güvenliği etkileyen faktörleri güvenlik ikliminin ölçülmesinde kullanmıştır (Zohar, 1980). Önleyici bir güvenlik kültürü yaratmak için olumlu bir güvenlik iklimi kurulması gereklidir (Cheyne, Cox, Oliver ve Tomás, 1998; Wu, Chi ve Mu, 2007).

Güvenlik kültürü kavramı ilk olarak Uluslararası Atom Enerjisi Ajansı (IAEA) tarafından 1986 yılında Çernobil Faciası kapsamında hazırlanan başlangıç raporunda kullanılmıştır (Cox ve Flin, 1998). Güvenlik kültürü değerler, inanışlar ve davranışlarla çerçevesi çizilen; kişi, iş, örgüt ve aralarındaki etkileşimler olarak tanımlanmaktadır. Güvenlik kültürünün ölçülmesi için yönetimin tutum ve davranışları, verilen eğitimler, çalışanlar ve yöneticiler arasındaki güvenlik iletişiminin yanı sıra kaza ve hastalıklarla ilgili raporlamalar da kullanılmaktadır (Cooper, 2002; Saraç, 2016; Cheyne ve Cox, 2000; Akalp ve Yamankaradeniz, 2013).

Yorulmaz ve ark. güvenlik iklimini çalışanların çalışılan çevre, çalışma ortamındaki uygulamalar ve ekonomik faktörlere göre çalışma güvenliğine karşı gösterdikleri psikolojik alg1 olarak tanımlamış ve iklimin alg1 ile kültürün ise tutumlarla ilgili olduğunu ifade etmişlerdir (Yorulmaz, Büyük ve Birgün, 2016). Cooper, yönetici ve uygulayıcıların bakış açısıyla güvenlik iklimini "güvenliğin gelişimi için uygulayıcı kontroller ve politikalarla önceden belirlenmiş işlevlere sahip olmak" olarak ifade etmiştir (Cooper, 2002). Ceyhun ise güvenlik iklimini; bir işyerinde çalışanların o iş yeri ile ilgili olarak paylaştıkları iş çevresi, çalışma ortamı ve çalışmaları sırasında karşılaştıkları riskler gibi paylaştıkları algılar olarak tanımlar (Ceyhun, 2014). Neal ve Griffin güvenlik iklimi algısı ve çalışanların beyan ettikleri güvenli davranışlar arasında aynı yönlü ve bunlarla iş yeri kazaları arasında ters yönlü bir ilişki olduğu ve kaza geçiren çalışanların kendilerini daha az güvende hissettikleri için güvenlik ikliminin son derece yetersiz olduğunu rapor ettiklerini söylerler (Neal ve Griffin, 2006). Bireysel tavır ve davranışları güvenlik ikliminin bir parçası olarak değerlendirmeyen Kines ve ark. güvenlik iklimini sosyal birimlerin, yönetimin ve çalışma gruplarının güvenlik politikaları, süreçleri ve uygulamaları, belirli bir zamanda paylaştıkları algı olarak tanımlarlar (Kines vd., 2011). Güvenlik ikliminin amacının oluşacak güvenlik kapsamında ortaya çıkacak olan sorunları önlemek olduğunu ifade eden Özdemir 
ve ark. güvenlik algılarının olumlu olmasının çalışanların iş performanslarını olumlu etkilediğinin ortaya koymuşlardır (Özdemir, Erdem ve Kalkın, 2016). Çalışma ortamındaki güvenlik iklimini etkileyen ve iş yerindeki kazaların oluşmasıyla arasında doğru orantı olan örgüt veya işyeri stresi, çalışanların psikolojik olarak verdikleri karşıllı̆ı olumsuz olarak etkilemektedir. Bu olumsuzluklar da hipertansiyon, kalp ve dolaşım sistemi problemleri, baş ağrısı, dikkat eksikliği gibi fiziksel rahatsızlıklara dönüşmektedir (Woo, Park, Lim ve Cho, 2017; Şimşek ve Derin, 2018). Genellikle baskın mühendislik önlemlerle yönetilen güvenlik yönetiminin rotasının güvenlik iklimi olduğunu, güvenliğin gelişiminde kaza oranları, kaza ve ramak kala olaylarını reaktif yaklaşımdan proaktif yaklaşıma dönülmek için kullanıldığını söylemektedirler (Kines vd., 2011).

Zohar'ın güvenlik iklimi alt faktörlerinden birisi olan kadercilik bireyin gelecek ile ilgili hiçbir şey yapamayacağı inancından yola çıkar (Taylor, 1962). Kadercilikte kazalar ve yaralanmalar kaçınılamaz ve önlenemezdir. Kadercilik çalışma güvenliğini olumsuz etkileyen kendine güveni az olan çalışanın güçsüzlük ve umutsuzluğunun sonucu ortaya çıkmasına rağmen iş yeri eğitimleri ve alınan doğru önlemlerle pozitif yönlü değiştirilebilinir (Kiani ve Khodabakhsh, 2013).

\section{2. Üniversitelerin İş Sağlığı ve Güvenliği Açısından Değerlendirilmesi}

Üniversiteler ve meslek yüksekokulları sadece eğitim verilen yerler değil aynı zamanda içinde bulundukları toplumun ve yetiştirdiği insanlarla da gelecekte içinde yaşanacak toplumun şekillendirilmesinde önemli görevleri olan kurumlardır.

Güvenlik kültürü ve güvenlik iklimi ile ilgili çalışmalar incelendiğinde çoğunlukla endüstri ve sanayi çalışanları arasında çalışmaların sürdürüldüğü görülmektedir. Yükseköğretim kurumları yapısal ve işlevsel olarak bu kurumlardan daha farklıdır. Kamu hizmeti sağlayan eğitim kurumlarındaki ulusal ve uluslararası rekabet, gelişmekte olan bu pazarda yer edinmek ve edinilen yerin kalıcılığını sağlamak için gerekli olan sürekli iyileştirme, yeniden modelleme, kalıcı kurumsal ve örgütsel yenilik yoluyla gerçekleştirilmeye çalışılmaktadır. Diğer alanlardan en büyük farkı ise devletlerin dinamikleri ve değişimlerinin yanı sıra sanayi davranışları ve ekonomik işlemlere yön vermedeki rolü, iş firsatları yaratma ve diğer sektörlerle olan ilişkilerinin sonucu ortaya çıkan kompleks bir yapı olmasıdır (Ball, 2009). Üniversiteler endüstri ve sanayi iş kolları ile kıyaslandığında; geleneksel bakış açısıyla akademik personelin esnek çalışma saatleri, hafif iş yükü, konferans amaçlı yurt içi ve yurt dışı gezilere katılımları nedeniyle avantajlı ve düşük stresli iş kolu olarak değerlendirilirken, modern dünyada hızla büyüyen, farklı ülkelerden insanları ve kültürleri bünyesinde barındırmaları nedeniyle farklı örgüt kültürüne sahip ve farklı riskleri içinde barındıran kurumlar olarak tanımlanırlar (Gillespie, Walsh, Winefield, Dua ve Stough C, 2001; Venables ve Allender, 2006). Wu vd. üniversitelerde ve yüksekokullarda öğrenim gören öğrencilerin teorik bilgilerin yanı sıra uygulamalarda kullandıkları deney ve uygulama laboratuvarları, test alanları, akademik personelin kullandığı araştırma laboratuvarlarının sahip oldukları riskler açısından tehlikeli yerler olduğunu ifade ederler ( $\mathrm{Wu}$, $\mathrm{Chi}$ ve $\mathrm{Mu}$, 2007). Ülkemizde üniversiteler iş sağlığı ve güvenliği açısından az tehlikeli iş yerleri olarak tanımlanırlar.

Üniversitelerin sürdürülebilir olması sadece ulusal değil uluslararası öğrenci, program ve kurumsal hareketlilik ile mümkün olabilmekte ve ortak kalite anlayışı ile güvence altına alınmaktadır. Bu kalite anlayışı her bir çalışan ve eğitim gören öğrenci için iş sağlı̆̆ ve güvenliğinin temelini oluşturmaktadır.

Bu çalışma ülkemizde farklı şehirlerde eğitim veren fen fakültelerinin kimya bölümlerinde yürütülmüştür. Maddenin temel yapı taşları olan atom, moleküller ve benzeri tüm bileşiklerin analizi, sentezi ve diğer maddeler ile olan etkileşimini inceleyen kimya temel bir bilim dalıdır. Kimya bilimi kendi nesnesini oluşturan tek temel bilim olma özelliği nedeniyle diğer bilimlerden ayrılır. 4 yıllık kimya eğitimi sonucunda kimyagerlik unvanı alan kişiler bilimsel araştırma yapmak için eğitilirler. Bilimsel araştırmaları sırasında tıp, eczacılık, savunma sanayi, gıda, çevre, arkeoloji ve tüm mühendislik dallarıla ortak çalışmalar yürütmeleri gerekir. Kimyagerler sanayi alanında ise kimyasal analiz gerektiren kalite kontrol veya kimyasal üretim alanlarında görev yapar (chem.metu.edu.tr/prospective). 
Tüm dünyada kullanılan, üretilen veya başka bir maddeyi üretmek için kullanılan malzemelerin yapısının kimyasal maddeler olduğu düşünülürse en baştan kazaları engellemenin önemi zaten ortaya konulmuş olacaktır. Tüm dünyada olduğu gibi ülkemizde de tehlikeli maddeler bulunduran kuruluşlarda büyük endüstriyel kazaların önlenmesi ve muhtemel kazaların insanlara ve çevreye olan zararlarının en aza indirilmesi amacıyla, yüksek seviyede, etkili ve sürekli korumayı sağlamak için alınması gerekli önlemler ile ilgili usul ve esasları belirlemek için gerekli olan yasal düzenlemeler yapılmıştır. Tehlikeli kimyasallar patlayıcı, oksitleyici, çok kolay alevlenir, kolay alevlenir, alevlenir, toksik, çok toksik, zararlı, aşındırıcı, tahriş edici, alerjen, kanserojen, mutajen, üreme için toksik ve çevre için tehlikeli özelliklerden bir veya birkaçına sahip madde ve/veya karışımları kapsamaktadır. Ayrıca ülkemizde kullanılan kimyasal maddelerin depolanması ve bulundurulmalarıla ilgili olarak çıkartılan yönetmelikle de üniversite kampüslerinde kullanılan kimyasallar da dahil olmak üzere tüm kurumlarda kullanılan ve/veya depolanan kimyasalların güven altına alınması sağlanmaktadır (Resmi Gazete T:12.08.2013, S:28733; Resmî Gazete T:02.03.2019, S: 30702). 19. yüzyılın ortalarından itibaren laboratuvar metodu fen bilimleri öğretiminin temel öğelerinden biri olarak kabul edilmiştir (Alipaşa, Karamustafaoğlu, Sevim ve Karamustafaoğlu, 2002). Kimya laboratuvarları kimyasallar, cam malzemeler, elektrikli veya elektronik cihazlar gibi farklı birçok malzemenin aynı anda kullanıldığı dinamik ortamlardır. Gaz ocakları, yüksek hızlı santrifüjler, yüksek basınçlı cihazlar, yüksek 1Sı kullanan firınlar bunlara verilebilecek en temel örneklerdir. Kimya Laboratuvarları; patlamalar, aşındırıcı, tahriş edici, oksidan veya toksik kimyasalların kullanıldığı ortamlardır. Diğer yandan, kimyasalların yaptıkları kontrolsüz bileşikler sonucu ortaya çıkan gazlar gibi yaşanabilecek aksilikler ile laboratuvarda çalışanların sadece kendilerine ve çalışma arkadaşlarına değil doğaya da verebilecekleri olası zararlar nedeniyle çok dikkatli çalışma yapılması gereken yerlerdir (Marin, Muñoz-Osuna, Arvayo-Mata ve Álvarez-Chávez, 2019). Amerika Birleşik Devletleri'nde bağımsız bir devlet kurumu olan Kimyasal Güvenlik ve Tehlike Araştırma Kurulu (U.S. Chemical Safety and Hazard Investigation Board/CSB) büyük endüstriyel kazaların kök sebeplerinin akademik laboratuvarlarda olan güvenlik açıklarını işaret ettiğini söylemektedir (Marin vd., 2019).

Ülkemizde çalışanların yanı sıra stajyer öğrencilerin de İş sağllğı ve Güvenliği eğitimi yönetmeliklerle güvence altına alınan zorunlu bir eğitimdir (Resmî Gazete T:15.05.2013, S:28648). Kimya bölümlerinde eğitim gören öğrenciler zorunlu staj eğitimlerinden önce iş ortamında karşılaşabilecekleri tehlikelere karşı kendilerini korumaları için iş sağlığı ve güvenliği eğitimini almış olmaları önemlidir. Ayrıca laboratuvar çalışmalarından önce de akademik personel tarafından kimyasal güvenliğinin yanı sıra iş güvenliği ile ilgili de genel kurallar bütün öğrencilere anlatılarak gerekli önlemleri almaları sağlanır.

Amerikan Kimya Derneği Kimya Güvenliği Komitesi (CCS) raporlarında üniversite öğrencilerinin korunması için güçlü güvenlik kültürü gelişiminin önemini vurgulamaktadır (Marin vd., 2019). Wu vd., önleyici bir güvenlik kültürü yaratmak için olumlu bir güvenlik iklimi kurulması ve üstün güvenlik performansları sergilenmesi gerektiğini belirtirken, sadece finansal kaynaklar kullanılarak ve mühendislik yöntemleriyle işyeri güvenliğini sağlamaya çalışan kurumların güvenlik anlamında plato seviyesinde kalacağını, davranışsal ve yönetimsel güvenlik problemlerini çözmekte mühendislik yöntemlerinin yetersiz kalacağını ifade ederler (Wu vd., 2007). Akademisyenler ve uygulayıcıların uygulamalı psikoloji kullanarak çözüm üretmeye çalıştıkları güvenlik problemlerinde güvenlik iklimi anketleri güvenlik programlarının değerlendirilmesi ve güvenlik performanslarının geliştirilmesinde önemli bir araçtır ( $\mathrm{Wu}$, Chen ve Li, 2008).

Bu çalışmanın temel amacı; farklı şehirlerde bulunan devlet üniversitelerinin kimya bölümlerinde öğrenim gören lisans ve lisansüstü öğrencilerinin güvenlik seviyelerini güvenlik ikliminin yedi boyutundan kadercilik alt faktörü üzerinden değerlendirmeye çalışmaktır (ÇASGEM, 2017). Bu alanın seçilmesinin asıl sebebi her zaman tehlike ve riskleri bünyesinde barındıran kimya bölümünün hazır bulunurlukları bize mezuniyet sonrası sanayi ve endüstride görev yapacak genç kimyagerlerin nasıl bir güvenlik anlayışına sahip olduğunu ve topluma nasıl yön vereceklerini gösterecektir. 


\section{Materyal ve Yöntem}

Fen fakültesi kimya bölümlerinde eğitim gören öğrencilerin iş sağlığı ve güvenliği bağlamında güvenlik ikliminin belirlenmesinde kadercilik algısının rolü belirlenecek ve güvenlik ile ilgili düşünce ve davranış profillerine göre ölçülen güvenlik algılarının farklı üniversitelerde eğitim gören öğrenciler arasında benzerlik ve farklılık gösterip göstermediği ortaya çıkarılacaktır. Araştırmanın yöntemi veri seçimi, veri toplama araçları ve veri analizi basamaklarını içermektedir.

\subsection{Veri Seçimi}

Anket çalışması, Öğrenci Seçme ve Yerleştirme Merkezi (ÖSYM) tarafından yapılan üniversite giriş ve yerleştirme sınavının 2019 yılı taban puanları sonuçlarına göre devlet üniversiteleri arasında en çok tercih edilen ilk on üniversite içinde yer alan ve Türkiye'nin iki büyük şehri olan İstanbul ve Ankara'da yer alan üç üniversitede gerçekleşmiştir. Çalışmaya katılan üniversitelerden Orta Doğu Teknik Üniversitesi 4. sırada İngilizce, İstanbul Teknik Üniversitesi 6. sırada Türkçe ve Ankara Üniversitesi 10. sırada İngilizce eğitim vermektedir. Ankette kullanılacak ölçek için İstanbul Aydın Üniversitesi Lisansüstü Eğitim Enstitüsüne başvurularak 31.12.2019 tarih ve 2019/22 sayılı etik kurul onayı alınmış ve rektörlük kanalıyla çalışma yapılacak olan üniversitelerin ilgili bölümlerine gönderilmiştir. Üniversitelerden gelen izinler doğrultusunda elektronik ortamda ve yüz yüze anket yöntemleri kullanılarak anket çalışması başlatılmıştır. Bu Üniversitelerde öğretim gören toplam öğrenci sayısı 1494'tür (YÖK Atlas, 2019). Yapılan anket çalışmalarına 165 öğrenci katılmıştır. Araştırmada basit tesadüfi örnekleme yöntemi kullanılmıştır.

\subsection{Veri Toplama Araçları}

Öğrencilerin iş sağlığı ve güvenliği kapsamında güvenlik iklimi alt faktörü kadercilik algısını değerlendirildiği çalışmamızda Demirbilek (2005) tarafından oluşturulan 15 demografik soru kullanılmıştır (Demirbilek, 2005). Ankette kadercilik algısını ölçmek için kullanılan sorular Zohar (1980) tarafindan geliştirilen güvenlik iklimi ölçeğine dayanmaktadır. Bu çalışmada Tüzüner ve Özarslan (2011) tarafından Türkçeye uyarlanan ve daha önce ÇASGEM (2017) tarafından ülkemizde "Türkiye İstatistiki Bölge Birimleri Sınıflandırması Düzey-1" olarak adlandırılan 12 şehirde farklı sektörlerde faaliyet gösteren kurumların 2018 çalışanına uygulanan anket soruları kullanılmıştır (Tüzüner ve Özarslan, 2011; ÇASGEM, 2017).

Ölçekte kullanılan ifadeler 5'li Likert ölçeğine göre hiç katılmıyorum, biraz katılıyorum, orta derecede katılıyorum, çok katılıyorum ve tamamen katılıyorum olarak ölçeklenmiştir. Çalışmanın geçerliliği Tüzüner ve Özarslan tarafından 2011 yılında gerçekleştirildiği için tekrar test edilmemiştir (Tüzüner ve Özaslan, 2011) Ölçeğin Cronbach Alpha güvenilirlik katsayısı 0.927 olarak belirlenmiştir. İki yarı form arasında korelasyon, 0.74 olarak hesaplanmıştır). Veriler SPSS19 programı kullanılarak analiz edilmiş olup, $\% 95$ güven aralığında $\% 5$ hata payı ile çalışılmıştır.

Veriler basit tesadüfi yöntem kullanılarak gönüllü öğrencilerin katılımıyla yüz yüze ve elektronik ortamda Google anket yardımıyla toplanmıştır.

\subsection{Veri Analizi}

$\mathrm{Bu}$ çalışmada veri setinin daha iyi anlaşılabilmesi için tanımlayıcı istatistik yöntemler kullanılmıştır. Normal dağılıma uygunluğu test edilen verilerin tanımlanabilmesi ve açıklanabilmesi için ANOVA ve Ki-kare testleri uygulanmıştır. Ayrıca veriler faktör analizine tabii tutularak açıklayıcı ve tanımlayıcı analizlerin yapılması sağlanmıştır. Veriler SPSS 19 programı kullanılarak analiz edilmiştir. Anlamlılık düzeyi 0.5 olarak kabul edilmiştir. 


\section{Bulgular ve Tartışma}

\subsection{Demografik Bulgular}

Üç üniversiteden Fen Fakültesi Kimya bölümünde eğitim gören toplam 165 öğrenci çalışmaya katılmıştır. Araştırma sonuçlarının bilgileri Tablo 1'de özetlenmiştir. Araştırmaya katılan öğrencilerin \%66.7'i kadın ve \%33.3'ü erkektir. Öğrencilerin \%81.2'si 18-23 yaş aralığı içindedir. \%17.6 öğrenci 24-29; \%0.6 öğrenci 3035 ve \%0.6 öğrenci de 36-40 yaş grubundadır. Öğrencilerin \%43’ü 1. sınıf; \%29.1’i 2. sinıf; \%7.9’ü 3. sınıf; \%12.1'i 4. sınıf; \%5.5'i yüksek lisans ve \%2.4'ü doktora öğrencisidir.

Daha önce İSG eğitimi alan öğrencilerin oranı \%37 ve eğitim almayanların oranı \%63'tür. İSG eğitimi alanların içinde aldıkları eğitimi yeterli bulan öğrenci oranı \%37.2'dir. Bu öğrencilerin \%61.5'i aldıkları eğitimi yeterli bulmadı̆̆ını ifade etmişlerdir.

İş kazalarının nedenlerine bakıldığında; öğrencilerin \%64.2'si iş kazalarına sebep olarak diğer öğrencilerin uygun olmayan davranışlarını göstermektedir. Öğrencilerin \%18.2'si üniversite ortamının uygun olmamasını ve \%17.6'sı her iki durumun da etkili olduğunu belirtmişlerdir.

Tablo 1

Çalışma grubu bilgileri

Cinsiye

Kadın

$\begin{array}{ll}\mathbf{N} & \% \\ 110 & \% 66.7\end{array}$

Erkek

55

$\% 33.3$

\section{Eğitim durumları}

1. sinif

2. sinif

55

$\% 33.3$

3. sinif

$\% 43.1$

4. sinif

$\% 29.1$

Yüksek lisans

$\% 7.9$

Doktora

$\% 12.1$

$\% 5.5$

$\% 2.4$

İSG eğitimi aldınız mı?

Evet

1. sinif

$\% 37$

2. sinif

$\% 2.9$

3. sinif

$\% 41.7$

4. sinif

Yüksek lisans

Doktora

$\% 61.5$

$\% 40$

8
8

Hayır

3

$\% 75$

104

$\% 63$

Aldığınız İSG eğitimi yeterli mi?

Evet

1. sinif

2. sinif

3. sinif

4. $\sin 1 f$

Yüksek lisans

Doktora

Hayır

6

6

$\% 37$

$\% 37$

$\% 36$

7

1

2

$\% 14.3$

$\% 30$

$4 \quad \% 50$

$3 \quad \% 100$

37

$\% 63$

\section{Eğitim gördüğünüz üniversitede hiç iş kazası geçirdiniz mi?}

Evet

1. $\sin 1 \mathrm{f}$

2. $\sin 1 \mathrm{f}$

3. sinif

4. sinif

Yüksek lisans

$\begin{array}{ll}21 & \% 12.7 \\ 6 & \% 28.6 \\ 4 & \% 19 \\ 3 & \% 14.3 \\ 7 & \% 33.3 \\ 0 & \% 0\end{array}$


Tablo 1'in Devamı.

\begin{tabular}{|c|c|c|}
\hline $\begin{array}{ll} & \text { Doktora } \\
\text { Hayır } & \\
\end{array}$ & $\begin{array}{l}1 \\
144 \\
\end{array}$ & $\begin{array}{l}\% 4.8 \\
\% 87.3 \\
\end{array}$ \\
\hline \multicolumn{3}{|l|}{ ÍSG eğitimi aldıktan sonra iş kazası geçirdiniz mi? } \\
\hline Evet & 9 & $\% 40$ \\
\hline Hayir & 12 & $\% 60$ \\
\hline \multicolumn{3}{|l|}{ İş kazası geçirenlerin uzak kaldığı süre (65 kişi) } \\
\hline Uzak kalmadım & 57 & $\% 57$ \\
\hline $1-3$ gün & 4 & $\% 4$ \\
\hline 4-7 gün & 1 & $\% 1$ \\
\hline $8-14$ gün & - & - \\
\hline $15-21$ gün & 3 & $\% 3$ \\
\hline \multicolumn{3}{|l|}{ İş kazası geçirme nedenleri } \\
\hline Öğrencilerin uygun olmayan davranıșları & 106 & $\% 64.2$ \\
\hline Üniversitenin ortamının uygun olmaması & 30 & $\% 18.2$ \\
\hline İkisi birlikte & 29 & $\% 17.6$ \\
\hline \multicolumn{3}{|l|}{ Üniversitede mobinge uğradınız mı?(40 öğrenci) } \\
\hline Evet & 40 & $\% 24.4$ \\
\hline Hayır & 125 & $\% 75.6$ \\
\hline \multicolumn{3}{|l|}{ Kim tarafından mobinge uğradınız: } \\
\hline Yöneticiler (4öğrenci) & 4 & $\% 10$ \\
\hline Akademik Personel (11 öğrenci) & 11 & $\% 27.5$ \\
\hline Diğer Öğrenciler (12 öğrenci) & 12 & $\% 30$ \\
\hline Akademik Personel ve Diğer Öğrenciler (5 öğrenci) & 5 & $\% 12.5$ \\
\hline Yöneticiler ve Akademik Personel (3 öğrenci) & 3 & $\% 7.5$ \\
\hline Yöneticiler ve Diğer Öğrenciler (2 öğrenci) & 2 & $\% 5$ \\
\hline Hepsi (3 öğrenci) & 3 & $\% 7.5$ \\
\hline
\end{tabular}

Bu bölümde öğrencilerin güvenlik iklimini değerlendirmelerinin yaş, cinsiyet, öğrenim gördükleri üniversite, eğitimleri süresince geçirdikleri ramak kala olay ve/veya kaza, eğitim gördükleri üniversiteye olan bağlılıklar1; tercih sıraları, eğitim gördükleri üniversiteden memnuniyetleri, üniversitede mobinge maruz kalma ve aralarındaki ilişkiler analiz edilmiştir. Analizlerde iki kategorik verinin test edilmesini sağlayan ki-kare (Pearson's chi-square) testi kullanılmıştır.

Ankete katılan kadın öğrencilerin \%43'ü ve erkek öğrencilerin \%22'si iş kazası geçirmişlerdir. Ki kare (Pearson chi-square) testine göre iş kazası geçirmekle cinsiyet arasında herhangi bir ilişki yoktur ( $\mathrm{p}=0.910)$. Ankete katılan kadın öğrencilerin \%61'i ve erkek öğrencilerin \%31'i eğitim gördükleri üniversitede ramak kala olay yaşamışlardır. Yine (Pearson chi-square) ki-kare testine göre ramak kala olay ve cinsiyet arasında herhangi bir ilişki yoktur ( $\mathrm{p}=0.912$ ). Ankete katılan kadın öğrencilerin \%13'ü ve erkek öğrencilerin \%8'i eğitim gördükleri üniversitede iş kazası geçirmişlerdir. Aynı şekilde eğitim gördükleri üniversitede iş kazası geçirmeleri ile de cinsiyet arasında bir ilişki yoktur $(\mathrm{p}=0.620)$.

Ki-kare testine (Pearson chi-square) göre İSG eğitimi alanların \%40’1 iş kazası geçirmiştir ve eğitim alanlarla kaza geçirenler arasında anlamlı bir ilişki yoktur $(\mathrm{p}=0.516)$. Bunun nedeni ögrencilerin aldıkları eğitimin yetersiz olmasi olabilir.

\subsection{Faktör Analizi}

Ankette kadercilik ile ilgili soruların faktör analizine uygun olup olmadığını değerlendirmek amacıyla KMO ve Barlett's testi uygulanmıştır. Tablo 2'de gösterilen KMO değeri 0.5'ten büyük ve Barlett testi 0.01 'den küçük olduğu için faktör analizine uygundur. 35. soru çıkarılarak yapıldığında KMO ve Barlett testine göre $\mathrm{KMO}=0.889$ ve Barlett sig= 0.000 için anket sonuçları faktör analizi yapmak için uygundur. Çalışmada 
kullanılan ölçeğin çalışmanın \%59'unu açıkladığı görülmüştür. Ölçeğin Cronbach Alpha güvenirlik katsayıs1, 0.923 'tür.

Tablo 2

Kaiser-Meyer-Olkin (KMO) örneklem uygunluk ölçüsü ve Barlett küresellik testi

\section{KMO ve Bartlett Küresellik Testi}

Kaiser-Meyer-Olkin Örneklem Uygunluk Ölçüsü

Bartlett Küresellik Testi Yaklaşık Ki-kare test istatistiği df (serbestlik derecesi)

Sig. (p)
0,889

4842.567

1275

0,000

$\mathrm{Bu}$ çalışmada ölçülmek istenen "İş sağlığı ve güvenliği konusundaki kaderci yaklaşım" 6 soru ile ölçümlenmiştir.

Verilerin yorumlanabilmesi ve daha iyi özetlenebilmesi için tanımlayıcı analizler (descriptive statistics) kullanılarak ortalama ve standart sapmasını hesaplanmış ayrıca faktör yük değerleri ölçülerek maddelerin faktörle olan ilişkisi açıklanmaya çalışılmıştır. Tablo 3'de faktör yüklerine bakıldığında S1., S2. ve S3. soruların yüklerinin 0.60 'dan büyük olduğu için yüksek yük gücüne; S4., S5. ve S6. soruların orta yük gücüne sahip oldukları görülmüştür.

Tablo 3

Fen Edebiyat Fakültesi Kimya Bölümü öğrencileri için iş sağlığı ve güvenliği güvenlik düzeyi ölçeği faktör analiz sonuçları (pattern matrix)

\begin{tabular}{|c|c|c|c|}
\hline Faktör adı & $\%$ & İfade & Faktör yükü \\
\hline & & $\begin{array}{l}\text { S1: İşimde (laboratuvardaki deneyler } \\
\text { sırasında) risk almaktan kacınamam }\end{array}$ & 0.691 \\
\hline & & $\begin{array}{l}\text { S2: Üniversitede işlerin en k1sa yoldan } \\
\text { yapılması önemlidir. }\end{array}$ & 0.666 \\
\hline & & $\begin{array}{l}\text { S3: Ne yaparsam yapayım kazaların } \\
\text { gerçekleşmesini engelleyemem. }\end{array}$ & 0.656 \\
\hline \multirow[t]{3}{*}{ Faktör Kadercilik } & 7.913 & $\begin{array}{l}\text { S4: Kazalar öğrenciliğin bir parçası olarak } \\
\text { hoș görülür }\end{array}$ & 0.565 \\
\hline & & $\begin{array}{l}\text { S5: Üniversitede iş sağllğı ve güvenliğini } \\
\text { geliştirmek için hiç bir şey yapamam. }\end{array}$ & 0.540 \\
\hline & & $\begin{array}{l}\text { S6: Üniversitede sadece birkaç kişi iş sağllğ } 1 \\
\text { ve güvenliği ile ilgilenir }\end{array}$ & 0.519 \\
\hline
\end{tabular}

Üniversitelerin kadercilik faktörü karşısında birbirleriyle olan ilişkilerini değerlendirmek amacıyla tek yönlü ANOVA (one-way ANOVA) analizi kullanılmıştır. Kadercilik algısı açısından Tablo 4'e göre:

$\mathrm{H}_{0}=$ Üniversiteler kadercilik algısı açısından birbirlerinden bağımsızdırlar.

$\mathrm{H}_{1}=$ Üniversiteler kadercilik algısı açısından birbirlerine bağımlıdırlar.

Tablo 4

ANOVA analizi

\begin{tabular}{lrrcrrr} 
Faktör & Karelerin Toplamı & df & Ortalama Kare & F & Sig. & Hipotez Durumu \\
\hline FAC & & & & & & \\
Between Groups & 301787 & 2 & 150894 & 7265 & 0.001 & $\mathrm{H}_{0}$ reddedildi \\
Within Groups & 3364540 & 162 & 20769 & & & \\
Total & 3666327 & 164 & & & & \\
\hline
\end{tabular}


Üniversite öğrencilerinin kadercilik anlayışı incelendiğinde üniversitelerin birbirlerine bağlı oldukları yani öğrencilerin eğitim gördükleri üniversitelerden bağımsız olarak ortak bir eğilim gösterdiği görülmektedir. Bu durum örgütsel iklimde farklı kurumlarda çalışanlar güvenlik anlamında ortak bakış açılarına sahiptirler savını da desteklemektedir (Zohar, 1980).

Öğrencileri kadercilik anlayışının istatistiksel olarak yorumlanabilmesi için Tablo 5'te gösterilen frekans tablosu elde edilmiştir. Faktör yükü en yüksek olan sorudan en düşük olan soruya göre hazırlanan Tabloda öğrencilerin sorulara katılım oranları analiz edilmiştir.

Tablo 5

Kadercilik anlayışı istatistiksel analizi

\begin{tabular}{|c|c|c|c|c|c|}
\hline Faktör Kadercilik & $\begin{array}{c}\text { Hiç } \\
\text { katılmıyorum } \\
\text { Öğgrenci } \\
\text { sayısı } \\
\% \\
\end{array}$ & \begin{tabular}{c}
\multicolumn{1}{c}{ Biraz } \\
katulıyorum \\
\multicolumn{1}{c}{ Öğrenci } \\
sayısı \\
\multicolumn{1}{c}{$\%$} \\
\end{tabular} & $\begin{array}{c}\text { Orta derecede } \\
\text { katılıyorum } \\
\text { Öğrenci } \\
\text { sayısı } \\
\% \\
\end{array}$ & $\begin{array}{c}\text { Çok } \\
\text { katılıyorum } \\
\text { Öğgrenci } \\
\text { sayısı } \\
\% \\
\end{array}$ & $\begin{array}{c}\text { Tamamen } \\
\text { katılıyorum } \\
\text { Öğgrenci } \\
\text { sayısı } \\
\quad \% \\
\end{array}$ \\
\hline $\begin{array}{l}\text { S1: İşimde } \\
\text { (laboratuvardaki }\end{array}$ & 53 & 38 & 47 & 13 & 14 \\
\hline $\begin{array}{l}\text { deneyler sırasında) } \\
\text { risk almaktan } \\
\text { kaçınamam. }\end{array}$ & 32.1 & $\begin{array}{l}50 \\
23\end{array}$ & $\begin{array}{r}41 \\
28.5\end{array}$ & $\begin{array}{l}15 \\
7.9\end{array}$ & $\begin{array}{l}14 \\
8.5\end{array}$ \\
\hline $\begin{array}{l}\text { S2: Üniversitede } \\
\text { işlerin en k1sa yoldan } \\
\text { yapılması önemlidir. }\end{array}$ & $\begin{array}{r}25 \\
15.2\end{array}$ & $\begin{array}{r}47 \\
28.5\end{array}$ & $\begin{array}{r}48 \\
29.1\end{array}$ & $\begin{array}{r}20 \\
12.1\end{array}$ & $\begin{array}{r}25 \\
15.2\end{array}$ \\
\hline $\begin{array}{l}\text { S3: Ne yaparsam } \\
\text { yapayım kazaların }\end{array}$ & 56 & 44 & 43 & 9 & 13 \\
\hline $\begin{array}{l}\text { gerçekleşmesini } \\
\text { engelleyemem. }\end{array}$ & 33.9 & 26.7 & 26.1 & 5.5 & 7.9 \\
\hline S4: Kazalar & 54 & 40 & 40 & 19 & 12 \\
\hline $\begin{array}{l}\text { ogrenciligin bir parças1 } \\
\text { olarak hoş görülür. }\end{array}$ & 32.7 & 24.2 & 24.2 & 11.5 & 7.3 \\
\hline $\begin{array}{l}\text { S5: Üniversitede iş } \\
\text { sağllọ̆ } 1 \text { ve güvenliğini }\end{array}$ & 1 & & 4 & 10 & 8 \\
\hline $\begin{array}{l}\text { geliştirmek için hiç bir } \\
\text { şey yapamam. }\end{array}$ & 44.8 & 18.2 & $\begin{array}{r}43 \\
26.1\end{array}$ & 6.1 & $\begin{array}{r}8 \\
4.8\end{array}$ \\
\hline $\begin{array}{l}\text { S6: Üniversitede } \\
\text { sadece birkaç kişi iş }\end{array}$ & 53 & 28 & 57 & 18 & 9 \\
\hline $\begin{array}{l}\text { sağlığı ve güvenliği ile } \\
\text { ilgilenir. }\end{array}$ & 32.1 & 17 & 34.5 & 10.9 & 5.5 \\
\hline
\end{tabular}

Faktör yükü en yüksek olan 1. soruda öğrencilerin sadece $\% 32.1$ 'i deneyler sirasinda risk almaktan kaçınamayacağını düşünüyor bu da öğrencilerin \%67.9'u ciddi herhangi bir risk gerçekleşeceğinde o riski almayacağını göstermektedir. Öğrencilerin \%37.3’ü üniversitede işlerin en kısa yoldan yapılması çok önemlidir derken \%15.2'si bu düşünceye hiç katılmamaktadır. Kazaların gerçekleşmesine engel olamayacağını düşünen öğrencilerin oranı orta, çok ve tamamen katılıyorum toplamında \%40'tır. Öğrencilerin sadece \% $\%$ 'i kazaların önüne geçilemeyeceğini düşünmektedir. Yine aynı şekilde kazaların öğrenciliğin bir parçası ve tamamen hoş karşılanan bir durum olduğunu düşünenlerin oranı sadece \%7.3'tür. Öğrencilerin \%32.7'si bu duruma hiç katılmazken sadece $\% 35$ 'i orta ve çok derecede katılmaktadır. Öğrenciler kazaların önüne geçebilecekleri ve güvenliklerini koruyup korumadıklarını test eden 5. soru ile iş sağlığı ve güvenliğini geliştirmek için uğraştıklarını ifade etmektedirler. Öğrencilerin sadece \%11'i iş kazalarını engellemek için iş sağlığı ve güvenliği konusunda fazla bir şey yapmadığını ifade etmiştir. Öğrencilerin kendileri gibi iş kazalarının engellenmesi için yönetimi değerlendirdikleri 6. soruda öğrencilerin \%49'unun yönetimin sadece birkaç kişiyle iş sağlığı ve güvenliği ile ilgilendiğini ifade ettikleri görülmüştür. Bu sonuçlar 
değerlendirildiğinde çok tehlikeli alanda eğitim alan Kimya bölümü öğrencilerinin kadercilik anlayışının düşük olduğu; iş kazalarının önüne geçileceğinin düşünüldügünü anlaşılmaktadır. Bu durum tehlikeli iş grubu olan marangozlarla Gökçe tarafından yapılan araştırmayla da desteklenmektedir (Gökçe, 2020). Yine AFAD ve itfaiye çalışanları ile yapılan başka bir çalışmada da çok tehlikeli olan bu gruplarda da iş güvenliği konusunda kaderci çalışmadıkları tespit edilmiştir (Motorcu ve Yılmaz, 2020). Kadercilik anlayışının eğitim seviyesi yükseldikçe düştüğü daha önce yapılan araştırmalarla da desteklenmektedir (Yıldırım, Akyüz, Aydın ve Alevli, 2015).

\section{Sonuçlar}

Bu çalışmada büyük endüstriyel kazaların önlenmesinde en önemli rolü oynayan Fen Fakülteleri Kimya bölümü öğrencilerinin eğitim gördükleri üniversitelerdeki güvenlik iklimi algıları güvenlik ikliminin alt faktörlerinden kadercilik ile iş kazaları, risk ve İSG eğitimi üzerinden açıklanmaya çalışılmıştır. Kadercilik anlayışı güvenliğe verilen önemi ve kontrol edilebilirlik algısını yansıtır. Güvenlik iklimini etkileyen diğer faktörlerden farklı olarak kadercilik anlayışı kaza geçirenlerin yaşadığı tecrübelerden veya işyeri hakkında farklı algılara sahip olan çalışanlarda değişiklik göstermez; kadercilik tüm bunlardan bağımsız olarak değişime direnç gösterir (Williamson, Feyer, Cairns ve Biancotti, 1997). Kadercilik faktörü ortalama değeri kimya bölümü öğrencilerinin kaderci yaklaşımla kazaları değerlendirmediklerini ve kazaların önlenmesi konusunda kendilerini, yönetimi, üniversitenin ortamını da sorumlu gördüklerini göstermektedir. Bu durum kaza nedenleri ile doğru orantılıdır. Tablo 1.'e göre de öğrenciler kaza nedenlerinde $\% 64.2$ oranında diğer öğrencilerin güvensiz davranışlarına, \%18.2'sini üniversitenin ortamının uygun olmamasına ve \%17.6'sını da her iki etmene birden bağlamışlardır. Yapılan literatür çalışmalarında eğitim seviyesi ve kadercilik arasında ters orantılı anlamlı farklar olduğu bilinmektedir. Eğitim seviyesi yükseldikçe kadercilik algısı azalmaktadır (Yıldız ve Y1lmaz, 2017; Yıldırım vd., 2015; Gökçe, 2020; Motorcu ve Yılmaz, 2020; Ruiu, 2012). İş yeri İSG eğitimlerinin de iş kazalarının ve meslek hastalıklarının önüne geçilmesi için önemli olduğu bilinmesine rağmen yapılan literatür çalışmalarında üniversite öğrencilerine verilen İSG eğitimlerinin güvenlik algılarını değişmesini sağlamadığı görülmektedir (Topgül ve Alan, 2017; Sivrikaya ve Üzüm, 2018). Bu çalışmada da İSG eğitimi alan öğrencilerle iş kazası geçirme arasında anlamlı bir fark olmaması bu savı desteklemektedir. Araştırmanın, endüstride özellikle çok tehlikeli sınıfta yer alan sektörlere insan kaynağı yetiştiren farklı teknik bölümler için genişletilmesi literatüre önemli katkı sağlayacaktır.

\section{Teşekkür}

Dr. Öğr. Üyesi Özge EREN'e çalışmaya olan katkılarından dolayı çok teşekkür ederiz.

\section{Yazar Katkıları}

Gülizar Hoşten: Verileri toplamış ve istatistiksel analizini yapmış, makaleyi yazmıştır.

Necla Dalbay: Çalışmayı ve analizlerini planlamış, makalenin düzenlenmesine katkı sağlamıştır. Çalışmanın genel kontrolünü gerçekleştirmiştir.

\section{Çıkar Çatışması}

Yazarlar arasında çıkar çatışması bulunmamaktadır.

\section{Kaynaklar}

Akalp, G. ve Yamankaradeniz, N. (2013). İşletmelerde güvenlik kültürünün oluşumunda yönetimin rolü ve önemi. Sosyal Güvenlik Dergisi, 3(2), 96-109. Erişim adresi: https://dergipark.org.tr/en/download/article-file/282936

Alipaşa, A., Karamustafaoğlu, S., Sevim, S. ve Karamustafaoğlu, O. (2002). Genel kimya laboratuvar uygulamalarının öğrenci ve öğretim elemanı gözüyle değerlendirilmesi. Hacettepe Üniversitesi Eğitim Fakültesi Dergisi, 2002(23), 50-56. Erişim adresi: https://dergipark.org.tr/en/download/article$\underline{\text { file/87917 }}$ 
Ball, S. J. (2009). Privatising education, privatising education policy, privatising educational research: Network governance and the competition state. Journal of Education Policy, 24(1), 83-99. https://doi.org/10.1080/02680930802419474

Ceyhun, G. Ç. (2014). Güvenlik iklimi ve iş-aile çatışmasının yorgunluğa etkileri: Türk kılavuz kaptanlar üzerine bir araştırma. Işsletme Araştırmaları Dergisi, 6(2), 91-105. Erişim adresi: https://www.isarder.org/2014/vol.6_issue.2_full_issue.pdf\#page=92

Chem.metu.edu, Erişim adresi: http://chem.metu.edu.tr/prospective, Aday Öğrenci. Erişim tarihi: Mayıs, 2020

Cheyne, A., Cox, S., Oliver, A. ve Tomás, J. M. (1998). Modelling safety climate in the prediction of levels of safety activity. Work and Stress, 12(3), 255-271. https://doi.org/10.1080/02678379808256865

Cheyne, A. J. T. \& Cox, S. J. (2000). Assessing safety culture in offshore environments. Safety Science, 34(13), 111-129. https://doi.org/10.1016/S0925-7535(00)00009-6

Cooper, D. (2002). Safety culture: A model for understanding and quantifying a difficult concept. Professional Safety, 30-36. Erişim adresi: https://www.behaviouralsafety.com/articles/safety_culture_understanding_a_difficult_concept.pdf

Cox, S. ve Flin, R. (1998). Safety culture: Philosopher's stone or man of straw?. Work and Stress, 12(3), 189201. https://doi.org/10.1080/02678379808256861

Çalışma ve Sosyal Güvenlik Bakanlığı, Çalışma ve Sosyal Güvenlik Eğitim ve Araştırma Merkezi. (2017). Türkiye'de iş sağlığı güvenliği algısı, ÇASGEM Rapor, Ankara. Erişim adresi: https://www.csgb.gov.tr/media/3234/turkiyede_issagligi.pdf

Demirbilek, T. (2005). İş güvenliği kültürü. Dokuz Eylül Yayınları, 1. Baskı, İzmir

Gillespie, N. A., Walsh, M., Winefield, A. H., Dua, J. ve Stough C. (2001). Occupational stress in universities: Staff perceptions of the causes, consequences and moderators of stress. Work \& Stress, 15(1), 53-72. https://doi.org/10.1080/02678370117944

Gökçe, A. (2020). İş sağlığı ve güvenliği açısından iş güvenliği kültürünün önemi üzerine bir odak grup çalışmas1. Ergonomi, 3(2), 82-95. https://doi.org/10.33439/ergonomi.749138

ILO, ILO Statistics and databases, Erişim adresi: http://www.ilo.org/global/statistics-and-databases/lang-en/index.htm.

Kiani, F. ve Khodabakhsh, M. R. (2013). The relationship between safety climate with fatalism and perceived helplessness among workers: Implication for health promotion. Journal of Community Health Research, 2(3), 196-207. Erişim adresi: https://www.sid.ir/en/journal/ViewPaper.aspx?id=452967

Kines, P. Lappalainen, J., Mikkelsen, K. L., Olsen, E., Pousette, A., Tharaldsen, J., Tómasson K. ve Törner, M. (2011). Nordic safety climate questionnaire (NOSACQ-50): A new tool for diagnosing occupational safety climate. International Journal of Industrial Ergonomics, 41(6), 634-46. https://doi.org/10.1016/j.ergon.2011.08.004

Marin, L. S., Muñoz-Osuna, F. O., Arvayo-Mata, K. L. ve Álvarez-Chávez, C. R. (2019). Chemistry laboratory safety climate survey (CLASS): A tool for measuring students' perceptions of safety. Journal of Chemical Health \& Safety, 26(6), 3-11. https://doi.org/10.1016/j.jchas.2019.01.001

Motorcu, A. R. ve Y1lmaz, K. (2020). Investigation of the effects of occupational safety supervisions on firefighting and AFAD teams' occupational safety cultures. International Marmara Sciences Congress, Kocaeli, Turkey, Proceedings e-book, 638-645. Erişim adresi: http://imascon.com/dosyalar/imascon2020bahar/imascon_fen_bildiriler_tammetin_bahar_2020.pdf

Neal, A. ve Griffin, M. A. (2006). A study of the lagged relationships among safety climate, safety motivation, safety behavior, and accidents at the individual and group levels. Journal of Applied Psychology, 91(4), 946-53. Erişim adresi: https://doi.org/10.1037/0021-9010.91.4.946

Özdemir, L., Erdem, H. ve Kalkın, G. (2016). Kamu çalışanlarının güvenlik iklimi algılarının tatmini ve iş performans1 üzerine etkisi. Süleyman Demirel Üniversitesi Vizyoner Dergisi, 7(15), 59-69. https://doi.org/10.21076/vizyoner.252106

Resmî Gazete (T:15.05.2013, S:28648). Çalışanların iş sağlı̆ğ ve güvenliği eğitimlerinin usul ve esasları hakkında yönetmelik. Erişim adresi: https://www.resmigazete.gov.tr/eskiler/2013/05/20130515-1.htm

Resmi Gazete (T:12.08.2013, S:28733). Kimyasal maddelerle çalışmalarda sağlık ve güvenlik önlemleri hakkında yönetmelik. Erişim adresi: https://www.mevzuat.gov.tr/mevzuat?MevzuatNo=18709\&MevzuatTur=7\&MevzuatTertip=5

Resmî Gazete (T: 02.03.2019, S:30702). Büyük endüstriyel kazaların önlenmesi ve etkilerinin azaltılması hakkında yönetmelik. Erişim adresi: https://www.resmigazete.gov.tr/eskiler/2019/03/20190302-1.htm 
Ruiu, G. (2012). Is fatalism a cultural belief? An empirical analysis on the origin of fatalist tendencies. Munich Personal RePEc Archive, MPRA Paper No. 41705. Erişim adresi: https://mpra.ub.unimuenchen.de/41705/

Saraç, Ç. K. (2016). İşsağlığl ve güvenlik kültürü algısının iş tatmini ile ilişkisinin incelenmesi (Yüksek Lisans Tezi No: 438393). Nişantaşı Üniversitesi Sosyal Bilimler Enstitüsü, İstanbul, Türkiye. Erişim adresi: https://tez.yok.gov.tr/UlusalTezMerkezi/

Sivrikaya Özkurt, S. ve Üzüm, B. (2018). Öğrencilerin işçi sağlığı ve güvenliğine yaklaşımları (Kocaeli MYO örneği). International Journal Of Disciplines Economics \& Administrative Sciences Studies, 4(7), 25872168. Erişim adresi: http://doi.org/10.26728/ideas.85

Şimşek, I. N. ve Derin, N. (2018). Güvenlik iklimi ve iş tatmini ilişkisinde birey-örgüt uyumunun aracı rolü. Atatürk Üniversitesi İktisadi ve İdari Bilimler Dergisi, 32(2), 231-245. Erişim adresi: https://dergipark.org.tr/tr/download/article-file/473664

Taylor, R. (1962). Fatalism. The Philosophical Review, 71(1), 56-66. https://doi.org/10.7312/wall15156-011

Topgül, S. ve Alan Ç. (2017). Öğrencilerin iş güvenliği ve iş güvenliği eğitimi algısının değerlendirilmesi. Süleyman Demirel Üniversitesi İktisadi ve İdari Bilimler Fakültesi Dergisi 22(2), 587-598. Erişim adresi: https://dergipark.org.tr/en/download/article-file/1004631

Tüzüner, V. ve Özaslan, B. (2011). Hastanelerde iş sağlığı ve güvenliği uygulamalarının değerlendirilmesine yönelik bir araştırma. İstanbul Üniversitesi İsletme Fakültesi Dergisi, 40(2), 138-154. Erişim adresi: https://dergipark.org.tr/en/download/article-file/98182

Venables, K. M. ve Allender, S. (2006). Occupational health needs of universities: A review with an emphasis on the United Kingdom. Occupational and Environmental Medicine, 63(3), 159-67. http://dx.doi.org/10.1136/oem.2005.022145

Williamson, A. M., Feyer, A. M., Cairns, D. ve Biancotti, D. (1997). The development of a measure of safety climate: the role of safety perceptions and attitudes. Safety Science, 25(1-3), 15-27. https://doi.org/10.1016/S0925-7535(97)00020-9

Woo, K. K., Park, S. J., Lim, H. S. ve Cho, H. H. (2017). Safety climate and occupational stress according to occupational accidents experience and employment type in shipbuilding industry of Korea. Safety and Health at Work, 8(3), 290-295. https://doi.org/10.1016/j.shaw.2017.08.002

Wu, T. C., Chi W. L. ve Mu C. L. (2007). Safety climate in university and college laboratories: Impact of organizational and individual factors. Journal of Safety Research, 38(1), 91-102. https://doi.org/10.1016/j.jsr.2007.01.003

Wu, T. C., Chen, C. H. ve Li, C. C. (2008). A correlation among safety leadership, safety climate and safety performance. Journal of Loss Prevention in the Process Industries, 21(3), 307-318. https://doi.org/10.1016/j.jlp.2007.11.001

Yorulmaz, M., Büyük, N. ve Birgün, S. (2016). Tersane işletmelerinde örgütsel güvenlik ikliminin incelenmesi. The Journal of Academic Social Science Studies, 5(46), 303-317. http://dx.doi.org/10.17719/jisr.2020.4043

Yıldırım, İ., Akyüz, K., Aydın, A. ve Alevli, C. (2015). Akdeniz bölgesi orman ürünleri sanayi çalışanlarının iş güvenliği algılarının belirlenmesi. Mühendislik Bilimleri ve Tasarım Dergisi, 3(3), 213-222. Erişim adresi: https://dergipark.org.tr/en/download/article-file/195452

Yıldız, S. ve Yılmaz, M. (2017). Türk inşaat sektöründe çalışanların güvenlik kültürü düzeyinin ve güvenlik performansı ile ilişkisinin incelenmesi. Politeknik Dergisi, 20(1), 137-149. Erişim adresi: https://dergipark.org.tr/en/download/article-file/467134

YÖK Atlas, (2019). Erişim adresi: https://yokatlas.yok.gov.tr/, Erişim tarihi: Ekim 2019

Zohar, D. (1980). Safety climate in industrial organizations: Theoretical and applied implications. Journal of Applied Psychology, 65(1), 96-102. https://doi.org/10.1037/0021-9010.65.1.96 